\title{
Contrasting beta diversity of spiders, carabids, and ants at local and regional scales in a black soil region, northeast China
}

\author{
Meixiang Gao ${ }^{1,2}$, Yuxi Guo ${ }^{3,4}$, Jie $\mathrm{Liu}^{5}$, Jinwen $\mathrm{Liu}^{4,6}$, Sina $\mathrm{Adl}^{7}$, Donghui $\mathrm{Wu}^{3,{ }^{*}}$, Tingyu $\mathrm{Lu}^{1,2}$ \\ 1 Department of Geography and Spatial Information Techniques, Ningbo University, Ningbo 315211, China \\ 2 Ningbo Universities Collaborative Innovation Center for Land and Marine Spatial Utilization and Governance Research at Ningbo \\ University, Ningbo 315211, China \\ 3 Key Laboratory of Wetland Ecology and Environment, Northeast Institute of Geography and Agroecology, Chinese Academy of Sciences, \\ Changchun 130012, China \\ 4 College of Earth Science, Jilin University, Changchun 130033, China \\ 5 College of Land and Tourism, Luoyang Normal University, Luoyang 471934, China \\ 6 Jilin Academy of Agricultural Sciences, Changchun 130033, China \\ 7 Department of Soil Science, College of Agriculture and Bioresources, University of Saskatchewan, 51 Campus Drive, Saskatoon, \\ SK S7N5A8, Canada
}

H I G H L I G H T S

- Ground arthropods distribution was compared at the local and regional scales.

- Beta-diversity finds distinct communities at the regional but not local scales.

- Turnover contributed more than nestedness of all arthropods at multiple scales.

- Spatial variables were important regulators at the local scale.

- Spatially structured environmental factors contributed most at regional scale.

\section{ARTICLE INFO}

Article history:

Received July 27, 2020

Revised October 22, 2020

Accepted October 30, 2020

\section{Keywords:}

Species turnover

Nestedness

Community structure

Agroecosystem
GRAPHICAL ABSTRACT
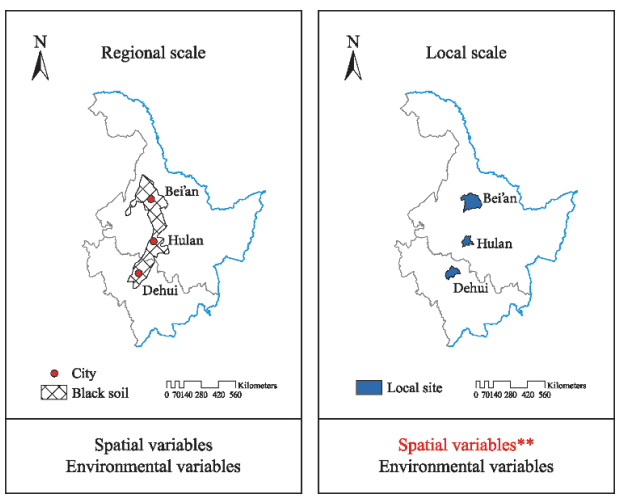

A B S TR A C T

Understanding the factors determining the formation of each community and metacommunity across a landscape is one of the most important ideas in soil animal ecology. However, the variables and parameters that shape soil arthropod communities in agroecosystems have not been resolved. These arthropods can serve as important bioindicators of field management and its sustainability. We sampled five corn plantations in each of three locations across a region spanning $600 \mathrm{~km}$ to come up with these determinants of the community structure of ground-dwelling spiders (Erigoninae: Araneae), carabids (Coleoptera: Carabidae), and ants (Hymenoptera: Formicidae). The analysis of the five fields within each of the three locations represent our local-scale samples, while the comparisons of the 15 sites across all three locations represent the regional scale samples. We tested the hypothesis that in the models we sampled, environmental/soil variables would drive 
community assembly locally (within location comparisons), but at the regional scale (between location comparisons), climatic and spatial variables would drive metacommunity assembly. The outcomes of our study showed distinct communities at each of the three locations when compared across regions but locally, fields were similar in species composition, as expected. Locally, spatial variables were important but not soil variables, regulated species richness and abundance. Turnover contributed more than nestedness to explain the biodiversity of spiders, carabids, and ants at both the local and regional scales. Neither purely climate variables, nor purely soil or spatial variables were significant enough explanations for the regional scale arthropod community composition. However, spatially structured environmental factors contributed most to explain the patterns supporting our hypothesis. We conclude that biodiversity in this agroecosystem area can be promoted by a mosaic of land uses being encouraged to increase landscape complexity at the regional scale.

(c) Higher Education Press 2020

\section{Introduction}

Frequent field disturbance by agriculture may promote habitat homogenization and cause biodiversity loss since it causes the destruction of some microhabitats (Murria et al., 2017; Landis, 2017). With frequent disturbance, sensitive or rare species tend to be lost, and over time promotes fewer species become tolerant to regular disturbance (Cerda et al., 2009). From these studies it was realized that the most probable cause for this loss and biodiversity simplification is reduced food availability and decreased niche availability by habitat fragmentation, for example, with detrimental effects on ground-dwelling carabids (Hendrickx et al., 2009).

Drivers of community assembly are scale dependent and can change with spatial scales (Lindo and Winchester, 2008; Li et al., 2020; Sreekar et al., 2020). Previous studies demonstrated that only limited to single scale may lead to biased conclusions (Sasaki and Yoshihara, 2013; BanaszakCibicka and Żmihorski, 2020) and studies at both local and regional scales allow researchers to identify the most important processes operating across multiple spatial scales (Benocci et al., 2015; Hamaoka et al., 2020). Biodiversity in farmland at local scale in turn leads to biodiversity at the regional scale. It is not straightforward to explain how the impact of biodiversity changes at local-scale effect biodiversity changes at regional scale. Technically, loss of one species at one location simply lowers the number of species by one at that location; and if it is a species found only at that site, it will contribute to a regional loss of one species. However, bearing in mind complicated species interactions, through the food web or by competition for resources, effects on one species affect the interdependent species, with consequences that ripple through the community and ecosystem. Compensation for local species losses in a community, and by stochastic processes mean that loss of species at local level has effect, be it large or small, on regional biodiversity (Hendrickx et al., 2009). Few studies have addressed biodiversity loss in agroecosystems at multiple scales (Pitta et al., 2017).

Identifying agroecosystem biodiversity and its underlying processes does not only consider the number of species and how many each species has, but also includes compositional differences among different communities at multiple scales. Beta diversity is the most direct and informative measure of variation in species composition at local sites across a landscape (Anderson et al., 2011). It is common knowledge that beta diversity patterns are determined by two distinct processes (Baselga, 2010): the turnover and the nestedness components. Turnover means that one species replaces another with no change in richness. Nestedness means that the difference in the richness of a community is as a result of species gain or loss (Baselga, 2010). Turnover and nestedness can be analyzed separately to identify variables/ processes that control species composition and richness variations at both local and regional scales. Mechanisms that bring about turnover originate from environmental filtering, competition, and historical events (Melo et al., 2009; Kraft et al., 2011). Mechanisms that bring about nestedness stem from species thinning, or from other ecological processes such as physical barriers of human disturbance (Baselga, 2010; Melo et al., 2009; Kraft et al., 2011; Legendre, 2015). However, the majority of studies on beta diversity have been conducted at one spatial scale or with aboveground ecosystems, thus shedding light to the lack of beta diversity studies for soil animal communities at local and regional scales.

Ecosystems with high structural complexity are spatially more heterogeneous, giving room for more diversity of resources, more niches, and therefore have greater soil arthropod diversity than simplified habitats (MacArthur et al., 1962; Gonçalves et al., 2018; Galle et al., 2018). Agroecosystems are known for reduced habitat heterogeneity especially at the local scale, therefore, farmland at the local scale contains lower species richness. Generally, a localscale community is a subset of a regional scale metacommunity and the regional scale metacommunity is an inventory of local-scale communities, thus, farmland at the regional scale usually has higher species richness (Simião-Ferreira et al., 2018). In addition, dispersal process among local communities was said to be a driving force for species richness in agroecosystems (Hendrickx et al., 2009). Logically, movement among the communities at a local scale is easy because of the short distance and more homogeneous spatial matrix. However, dispersion among local communities at the regional scale gets harder due to the long distance and increased spatial heterogeneity. Consequently, communities of soil animals at the local scale would be more similar in species richness and composition, but would be different in species richness and composition at the regional scale. Then, we expect distinctiveness of community compositions to exist at the regional scale but not at the local scale. Therefore, the turnover of beta diversity of soil animals is supposed to be higher at the regional scale than that at the local scale.

Habitat heterogeneity locally is as a result of variations in 
soil parameters that create various microhabitats. These soil parameters act as filters on species that affect species richness of the regional pool (such as water content, soil organic matter content) (Guo et al., 2019), and community structure at the local scale (such as soil organic matter content, water availability) (Zaitsev et al., 2013; Quist et al., 2019). Spatial processes operate at local and regional scales (Curry et al., 2015). Climate, altitude and latitudinal gradients, other environmental factors operate at the regional scale to shape community composition, while this has very little or no effect at all at the local scale (Ameline et al., 2017; Entling et al., 2010). Since the probabilities of successful dispersal among local communities are negatively correlated with the spatial distance between them, dispersal limitation of soil animals causes spatial structure in community composition. Accordingly, it is wise to think that soil variables are more important drivers at local scales, and climate and spatial variables are more relevant when considering regional scales for soil arthropod species distribution.

Spiders, carabids, and ants are successful natural enemies for pest control in agroecosystems (Eyre et al., 2016; Jacquot et al., 2017; Benhadi-Marín et al., 2020). They are sensitive agroecosystem bioindicators that have been used to monitor anthropogenic impact and agroecosystem health (Widhiono et al., 2017; Avgın et al., 2010; Borchard et al., 2014). Additionally, they are a practical tool for measuring variations in species richness and beta diversity at multiple sampling scales (Clough et al., 2007; Hendrickx et al., 2009; Koivula, 2011). For example, turnovers were the dominant components of beta diversity for spiders, carabids, and ants along elevational gradients, indicating the importance of dispersal limitation in community assembly (Fontana et al., 2020). Local changes in species composition of carabids affect beta diversity at the regional scale, which may have been caused by the depletion of low-dispersing carabids at the local scale (Hendrickx et al., 2009). And environmental factors at both local and landscape scales affect the functional beta diversity of spiders (Delgado de la flor et al., 2020). However, beta diversity of spiders, carabids, and ants at local and regional scales in agroecosystems is still not definite.

The purpose of this research was to examine beta diversity and its underlying variables of main ground-dwelling arthropods at local and regional scales. We tested the hypothesis that for spider, carabid, and ant community compositions, soil factors and climate, spatial factors were more relevant at the local and regional scales, respectively. Our hypothesis had it further that turnover components would be larger than nestedness components for all arthropods at the local and regional scales, and the turnover at regional scale was larger compared to that at the local scale. We measured (1) the species richness and abundance of spiders, carabids, and ants; (2) the beta diversity of spiders, carabids, and ants, partitioned between turnover and nestedness variables. We then (3) took into consideration how spiders, carabids, and ants relate with soil, climate, and spatial variables. We assumed that (1) species richness and abundance were lower at local scale but higher at regional scale; (2) overall beta diversity of spiders, carabids, and ants were lower at local scale but higher at regional scale, so that a difference in the structure of these arthropod communities would be detected at the regional scale, but not at the local scale.

\section{Material and methods}

\subsection{Study area}

The three selected local sites along latitudinal gradient locate in northeast China. Each local site had had corn cultivated continuously for more than 30 years. They were Beian (BA;

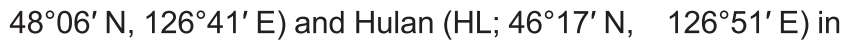
Heilongjiang Province, Dehui ( $\mathrm{DH} ; 44^{\circ} 35^{\prime} \mathrm{N}, 125^{\circ} 32^{\prime} \mathrm{E}$ ) in Jilin Province (please sea (Guo et al., 2019) for more information). The experiment was carried out in the black soil region with an average of organic matter content between $3 \%$ and $10 \%$. The black soil is usually highly fertile and is suitable for plant growth. The region is cold temperate semihumid with four seasons and mean annual temperature of $0.5-6^{\circ} \mathrm{C}$ (Cui et al., 2003). The annual average rainfall is 400 $700 \mathrm{~mm}$, with about $70 \%$ occurring July to September, often as heavy rainfall.

\subsection{Sampling spiders, carabids, and ants}

Five plots were set in each local site, with a separating partition of not less than $500 \mathrm{~m}$ between them. Within each plot, five sample points with measured spatial coordinates were selected to collect soil arthropods and soil samples (please see (Guo et al., 2019)). According to previous published studies, soil arthropods are abundant during growing seasons in black soil area (Yang et al., 2016; Liu et al., 2017). Therefore, samplings were carried out in June, July, and September in 2015, respectively. Pitfall traps were utilized in catching the ground-dwelling arthropods. Then a degradable plate was set above each trap about $10 \mathrm{~cm}$ to prevent litters and arthropods from the corn crop. Traps $(7-\mathrm{cm}$ diameter and $12-\mathrm{cm}$ depth) were active for seven days in the three months mentioned above. Each trap was filled with saturated sodium chloride solution. In each plot, 15 traps were collected from three traps $\times$ five sampling points. Therefore, there were 225 traps ( 15 traps $\times 5$ plots $\times 3$ local sites) every time the sampling was done, and all time points were pooled for this analysis. Three soil squares $(25-\mathrm{cm}$ length $\times 25-\mathrm{cm}$ width $\times 20-\mathrm{cm}$ depth) around each sampling point were dug at the same day using spades. Spiders, carabids, and ants were immediately collected by hands. Thus, a total of 450 samples were collected including the two sampling methods.

The ground-dwelling and belowground arthropods were preserved in $95 \%$ alcohol. They were identified to species level and counted with a binocular microscope. Larva and adults were separated for carabids because of the difference 
in morphology and habits. As a result of the low number of larva and the difficulties of identifying them, only adult carabids were included for subsequent data analysis. Considering the low count and species richness of belowground arthropods in this experiment, aboveground and belowground arthropods were combined, and then named as soil arthropods. There was a consent of the landowners to do the collection of the arthropods for the study.

\subsection{Statistical analysis}

Spiders, carabids, and ants sourced from a particular local site (BA, HL or $\mathrm{DH}$ ) were defined as communities. Arthropods collected from all three locations were termed as the communities at regional scale. Species richness and abundance of spiders, carabids, and ants were calculated at both local and regional scales.

As an evaluation for the effectiveness of our sampling, a sample-based rarefaction curve was used (Gotelli and Colwell, 2001; Crist and Veech, 2006). Communities with fewer than two species were not included in the local-scale rarefaction curve analysis. Therefore, 2,0 , and 3 communities were not included for spiders, carabids and ants at regional scale. The rarefaction curve analysis was not performed on communities of ants in BA and spiders in $\mathrm{DH}$ because of less than two species in all sampling points. The sample-based rarefaction curve was performed by specaccum function in "vegan" package in R 3.4.1 (Team, 2017).

Generalized linear mixed-effects models was utilized in evaluating the differences in species richness and abundance (Bolker et al., 2009; Zuur et al., 2009). We included regional sites as fixed factor and local sites as random factor in the model for abundance and richness at regional scale. We included plots as fixed factor and quadrats as random factor in the model at local scale. The models assumed Poisson error distributions for abundance and richness, and we confirmed that the model residuals were not over-dispersed. Data analysis were performed by glmer function in "Ime4" package using R 3.6.2 (Bates, 2010).

To evaluate whether community compositions of spiders, carabids, and ants were unique across plots at the local scale, and across local sites at the regional scale, a non-metric multidimensional scaling (NMDS) using the site-by-species matrix in abundance was employed. The NMDS was conducted with metaMDS function in "vegan" package in $\mathrm{R}$ 3.6.3 (Oksanen et al., 2017).

To examine the change in composition of the community among the five plots at the local scale and among the three local sites at the regional scale, beta diversity was calculated. The beta diversity of spiders, carabids, and ants was determined using multiple-site indices based on presenceabsence species data at local and regional scales. For both indices, the Sorensen dissimilarity was used to make the calculations, resulting in the following three dissimilarity coefficients: (1) Sorensen coefficient (i.e., a measure of overall beta diversity, $\beta_{S O R}$ ), (2) Simpson coefficient (i.e. a measure of turnover immune to nestedness derived from species richness differences, $\beta_{S I M}$ ), and (3) a coefficient measuring nestedness-resultant beta diversity ( $\beta_{\mathrm{SNE}}$ ) (BaseIga, 2010). The Simpson coefficient explains species turnover without being affected by richness gradients, whereas the nestedness component of beta diversity is the direct difference between $\beta_{\text {SOR }}$ and $\beta_{\text {SIM }}$. The three beta diversity coefficients were calculated using the functions betapart.cor and beta.multi using the R package "betapart" (Baselga et al., 2013). In the beta diversity calculations, communities with less than two species were eliminated, because low numbers of species produce unstable beta diversity estimates since the change of a single species could have adverse effects. We did not use a larger threshold because soil arthropod richness in the farmland was low, and higher thresholds would dramatically reduce our sample number.

To remove the relative importance of variables at both local (including soil and spatial variables) and regional scales (including soil, climatic and spatial variables) on the arthropod compositions, a variation partitioning method was used (Legendre and Legendre, 1998; Blanchet et al., 2014). Soil variables were measured for each sampling point in June 2015 and included soil organic matter content (SOM), soil pH and total nitrogen ( $\mathrm{TN}, \mathrm{g} \mathrm{kg}^{-1}$ ) (Appendix A1). The collected soil samples were air-dried at controlled temperature for one week and sieved with $1 \mathrm{~mm}$ mesh size. Then SOM (Anne's method described by Duchaufour (1976)), pH (Pansu et al., 2003) and TN (Kjeldahl's method described by Duchaufour (1976)) were measured in public technical service center of Northeast Institute of Geography and Agroecology, Chinese Academy of Sciences (http://service.iga.cas.cn/). Climatic factors were collected from published articles for three local sites, and included mean annual temperature $\left({ }^{\circ} \mathrm{C}\right)$, mean annual precipitation $(\mathrm{mm})$, annual frost-free period (days), mean annual hours of sunshine (hours), and maximum depth of frozen earth $(\mathrm{m})$ (Appendix B1). Based on geographical coordinates, principal coordinates of neighbor matrices (PCNM) was used to measure spatial variables. PCNM variables represent a spectral decomposition of the spatial relationships among the study sites (Dray et al., 2006). At local scale, 2, 2 and 2 PCNM variables were selected for spiders, carabids, and ants in BA; 2, 1 and 1 PCNM variables were selected for spiders, carabids, and ants in $\mathrm{HL} ; 7,7$, and 1 PCNM variables were selected for spiders, carabids, and ants in $\mathrm{DH}$ (Appendix A2). At regional scale, there were 1, 1, and 1 PCNM variables for spiders, carabids, and ants (Appendix A3). Soil and PCNM variables were utilized at local scale, and soil, climatic and PCNM variables were used at regional scale. Then a partial redundancy analysis ( $P R D A$ ) was employed to differentiate the total variation of a presence-absence species matrix into fractions that represents the contributions of the pure soil, pure climate, pure PCNM and their shared fractions (spatially structured environmental factors) (Peres-Neto et al., 2006). The importance of every source of variation was evaluated with a Monte Carlo permutation test (999 permutations). The PCNMs were calculated with the PCNM function in 
"PCNM" packages in R software. The variation partitioning was performed with varpart function and significance evaluation was performed with anova.cca function in the "vegan" package in $\mathrm{R}$ software.

\section{Results}

\subsection{Diversity at the local scale}

In total, 12, 9, 7 species and 136, 359, 2386 individuals were collected for spiders, carabids and ants, respectively (Appendix B2). Significant differences were only realized between plots IV-V for carabid abundance in BA (Fig. 1A and B). Significant differences were observed between different plots for carabid species and ant abundance in HL (Appendix A4(a), (b)). Significant differences were detected between different plots for spider, carabid and ant abundance in $\mathrm{DH}$ (Appendix A4-(C), (D)).

Ant abundance was significantly lower than carabid abundance $(p<0.05)$ in BA. The number of ants was notably higher compared to that of both the spider and carabid in both $\mathrm{HL}$ and $\mathrm{DH}(p<0.05)$. Species richness of ants was significantly lower than that of spiders in BA and significantly lower than that of carabids in $\mathrm{DH}(p<0.05)$. While species richness of ants was significantly higher than that of spiders and carabids in $\mathrm{HL}(p<0.05)$.

The sampling efforts were sufficient to examine the overall species richness of carabids and ants in $\mathrm{HL}$ and $\mathrm{DH}$, while the curves of spiders were relatively sharp in $\mathrm{BA}$ and $\mathrm{DH}$ (Appendix A5). The distinctiveness of plots was not noted for spiders, carabids, and ants in each local site, inferring relatively low turnover across five plots at local scale (Fig. 2).
A
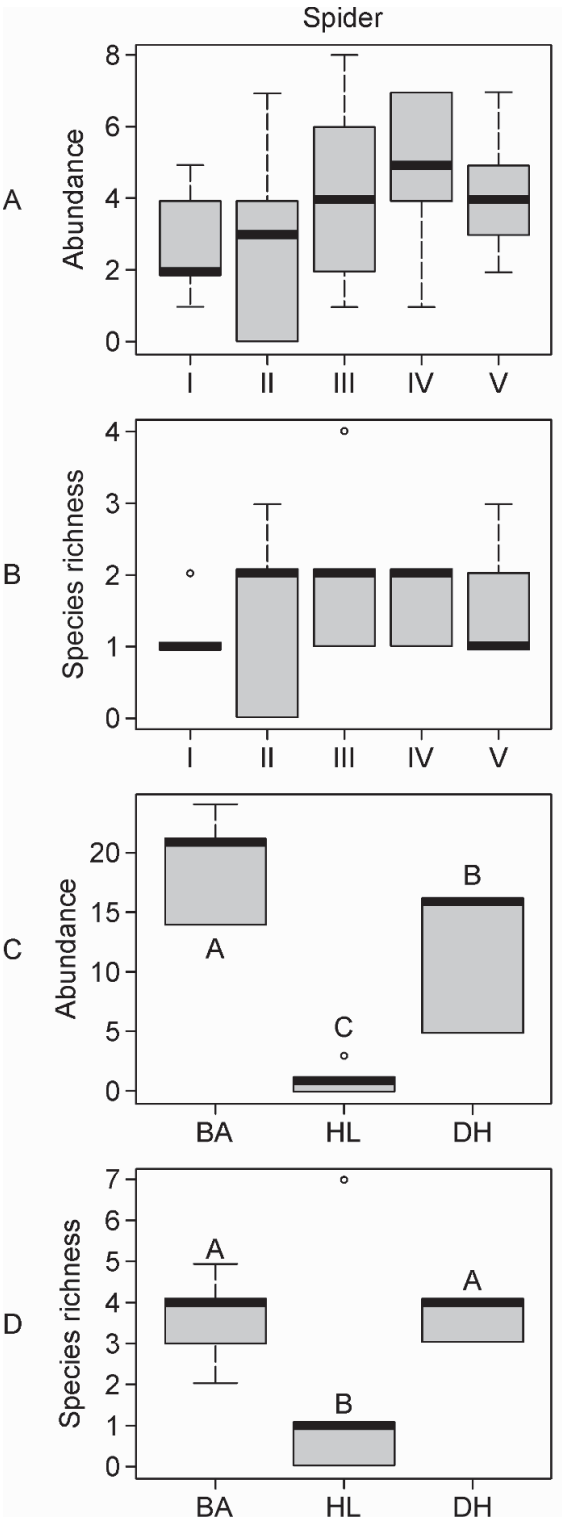

Carabid
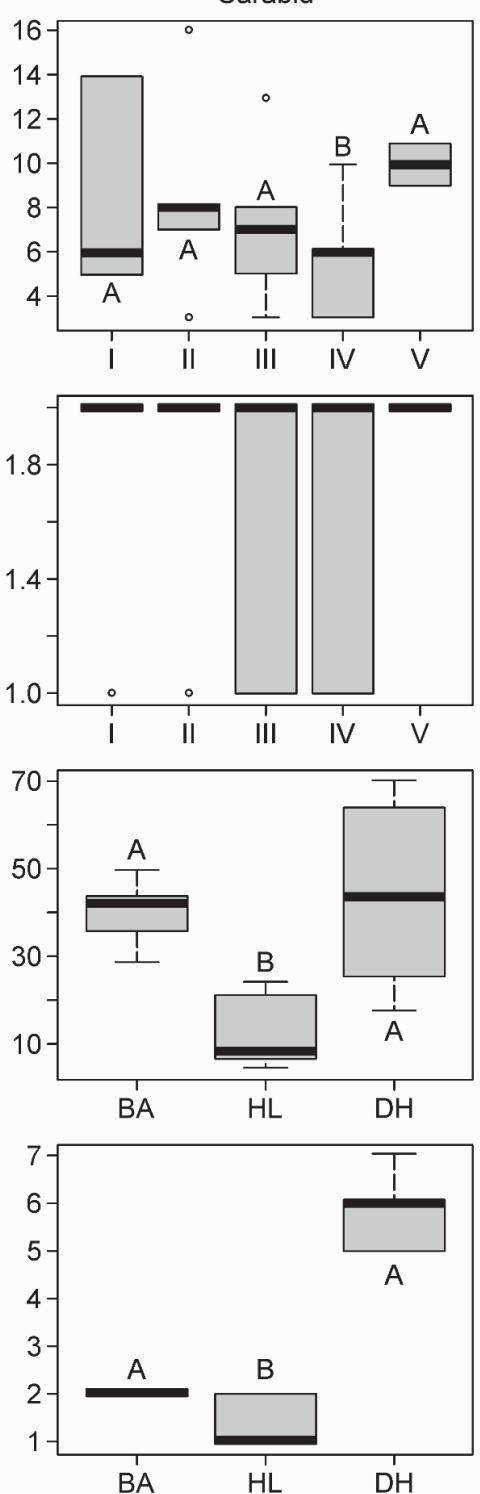
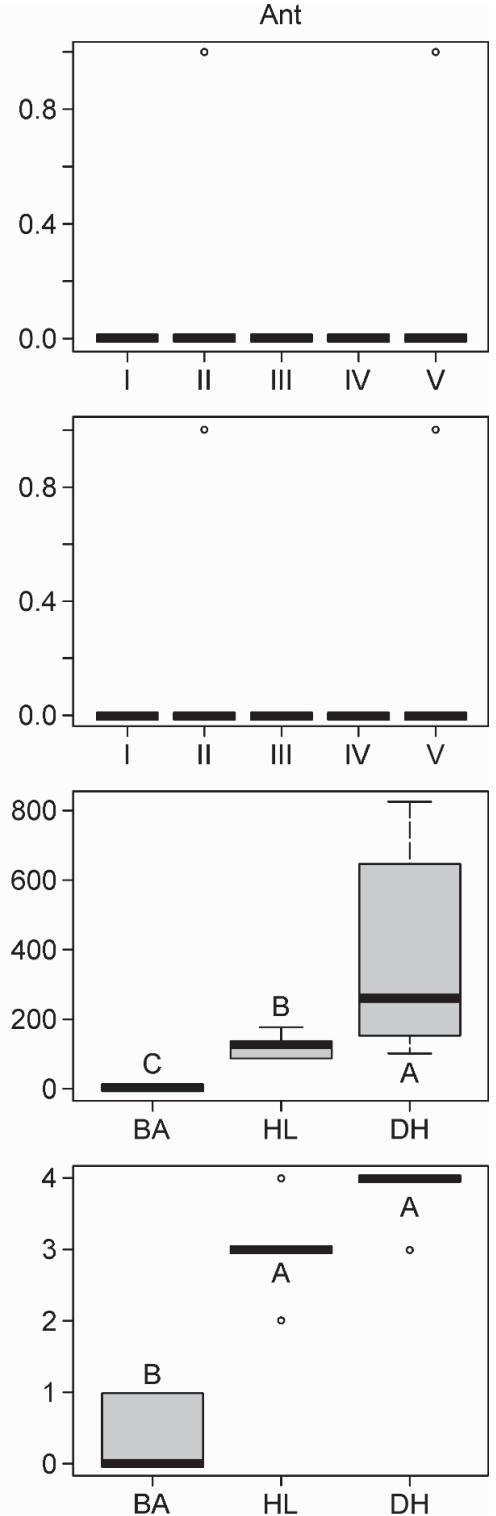

Fig. 1 Abundance and species richness of spiders, carabids and ants at BA local scale [(A), (B)] and regional scale [(C), (D)]. Different capital letters mean significant differences. Hollow circles indicate outliers. 
The turnover component of beta diversity $\left(\beta_{\mathrm{SIM}}\right)$ was larger than nestedness component ( $\beta_{\mathrm{NES}}$ ) of spiders, carabids, and ants at all local sites (Table 1). The overall beta diversity of ants was higher than that of carabids in HL. However, the turnover component of ants was lower compared to that of carabids, inferring low spatial turnover among the five plots for ants than that for carabids. The overall beta diversity of ants was lower in comparison to spiders and carabids in $\mathrm{DH}$, and the turnover of ants was the lowest among the three arthropods. The beta diversity of spiders, carabids, and ants were the highest in $\mathrm{DH}, \mathrm{HL}$, and $\mathrm{BA}$, respectively (Table 1).

Both carabids and ants in $\mathrm{HL}$ were controlled by purely PCNM factors, inferring important regulators of pure spatial factors. However, spiders, carabids, and ants were controlled neither by soil nor PCNM variables in both BA and DH (Fig. 3).

\subsection{Diversity at the regional scale}

Abundance of ants was significantly larger compared to spiders at regional scale $(p<0.05)$. Abundance and species richness of spiders, carabids, and ants were notably lowest in $\mathrm{HL}, \mathrm{HL}$, and BA, respectively (Fig. 1C, D). The sampling efforts gave a sufficient description of the overall species richness of carabids and ants at regional scale. However, the curve for spiders was still increasing (Appendix A6). The uniqueness in community composition were relatively high for spiders and ants, translating to relatively high turnover for these arthropods across the three local sites at regional scale (Fig. 4). Overall beta diversity $\left(\beta_{\mathrm{SOR}}\right)$ was the highest for spiders and the lowest for carabids. The turnover component of beta diversity $\left(\beta_{\text {SIM }}\right)$ across the three local sites had the major contribution to overall beta diversity for all arthropods at regional scale $\left(\beta_{\text {SOR }}\right): 80,71$ and $64 \%$ for spiders, carabids,
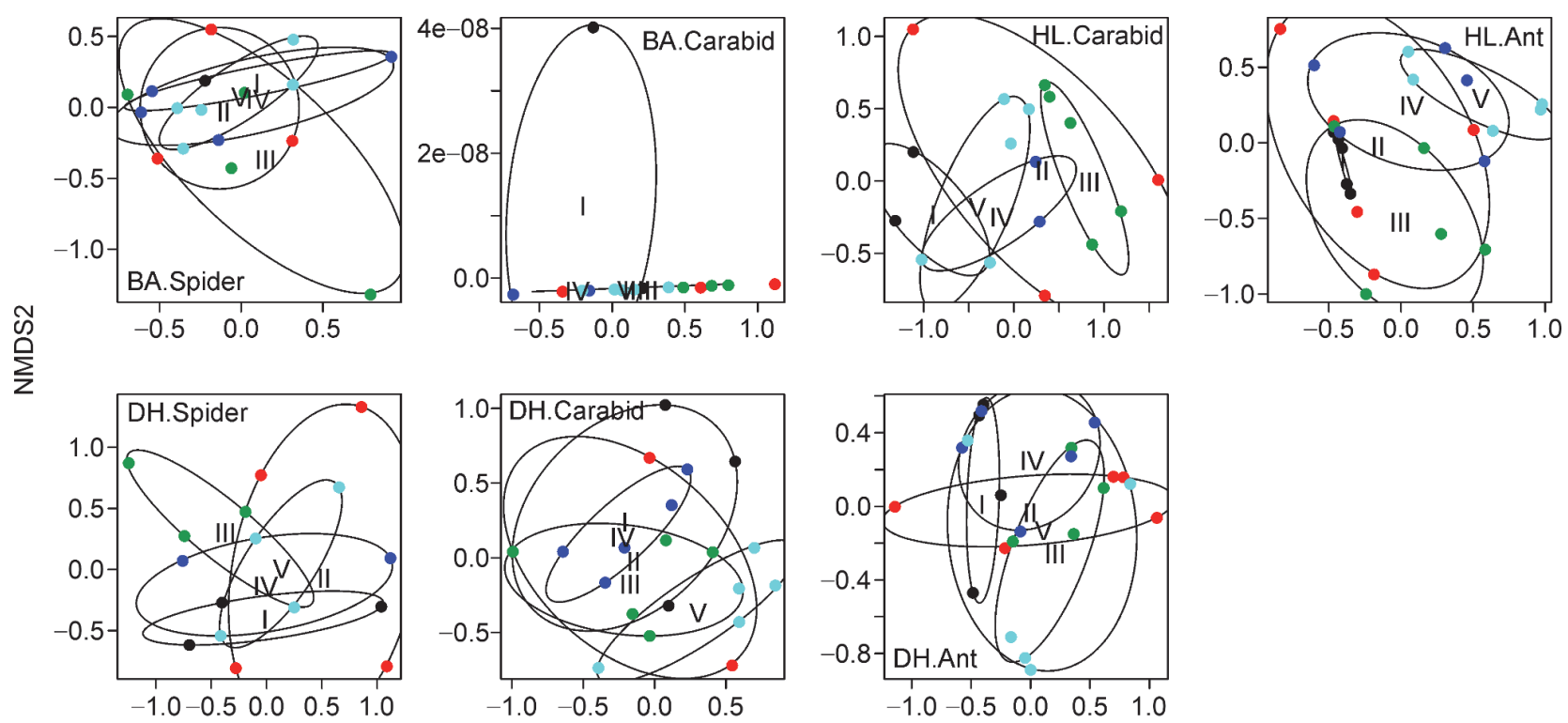

This research found that each $\mathrm{BA}, \mathrm{HL}$, and $\mathrm{DH}$ local site contributes similarly to the overall species pool at the regional scale because the species dissimilarity across local sites is mostly as a result of species replacement rather than by species richness change (Dunck et al., 2016). Therefore, in view of the representativeness of the three local sites across the black soil area, we make a conclusion that the local biodiversity simplification in the black soil agricultural region do not cause a significant biodiversity decrease at the regional scale. Since biodiversity homogenization at each local site causes a larger species compensation among different local sites, biodiversity increases instead of decreasing at the regional scale.

One of the main aims of soil animal ecology is to come up with factors regulating the composition and distribution of communities, and the causes underlying the distributions at multiple scales. Local environmental filtering has been suggested as a key regulatory factor on soil arthropods (Kovács-Hostyánszki et al., 2013; Liu et al., 2016). Some published literatures found that soil variables filter assem-
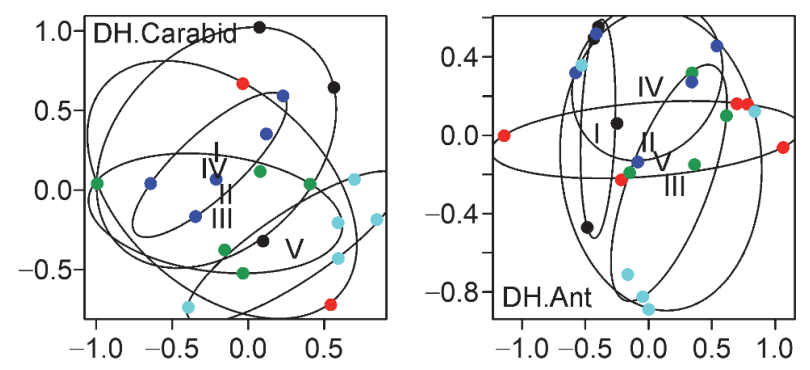

NMDS1

Fig. 2 Non-metric multidimensional scaling (NDMS) ordination for spiders, carabids, and ants at local scale for BA, $\mathrm{HL}$, and DH and at local scale. The ellipses envelop $95 \%$ plots of each local site. 
Table 1 Partitioning of beta diversity into species turnover $\left(\beta_{\mathrm{SIM}}\right)$ and nestedness $\left(\beta_{\mathrm{NES}}\right)$ of species community for spiders, carabids and ants at local and regional scales.

\begin{tabular}{|c|c|c|c|c|}
\hline Scale & Site & Arthropod & Turnover $\left(\beta_{\mathrm{SIM}}\right)$ & Nestedness $\left(\beta_{\mathrm{NES}}\right)$ \\
\hline \multirow[t]{9}{*}{ Local scale } & \multirow[t]{3}{*}{ BA } & Spider & 0.58 & 0.28 \\
\hline & & Carabid & 0 & 0.71 \\
\hline & & Ant & 1 & 0 \\
\hline & \multirow[t]{3}{*}{ HL } & Spider & 0 & 0.89 \\
\hline & & Carabid & 0.80 & 0.12 \\
\hline & & Ant & 0.50 & 0.50 \\
\hline & \multirow[t]{3}{*}{$\mathrm{DH}$} & Spider & 0.81 & 0.11 \\
\hline & & Carabid & 0.50 & 0.34 \\
\hline & & Ant & 0.43 & 0.32 \\
\hline \multirow[t]{3}{*}{ Regional scale } & & Spider & 0.80 & 0.08 \\
\hline & & Carabid & 0.71 & 0.11 \\
\hline & & Ant & 0.64 & 0.19 \\
\hline
\end{tabular}

$\mathrm{BA}, \mathrm{HL}$, and $\mathrm{DH}$ are three local sites.

blages of spiders (Ziesche and Roth, 2008), carabids (Pakeman and Stockan, 2014) and ants (Schmidt et al., 2017) at the local scale. To the contrary, several studies discovered a weak relationship between soil properties and spider ( $\mathrm{Li}$ et al., 2018), carabid (Liu et al., 2006), and ant (Jacquemin et al., 2012) communities, respectively. Soil properties were relatively homogenous with irrelevant differences among most plots at local sites in the study area (Appendix A1). In our study, soil variables were not relevant control factors for all arthropods at BA, HL, and DH local sites. However, community compositions of carabids and ants at local sites were significantly regulated by purely spatial variables (PCNM), partly supporting dispersal-based processes acquired from neutral theory (Heino et al., 2017). Hendrickx et al. (2009) argued that dispersal limitation has an effect on community composition of ground carabids in agriculture habitats because of the landscape fragmentation. Although the patch isolation or connections were not clearly stipulated in this study, they noted that fragmentation at each local site was not severe. Furthermore, topographic factors (such as altitude, slope, and orientation of a field) have been proven to affect the composition and distribution of carabids (Schuldt and Assmann, 2011) and ants (Crist and Wiens, 1996). In our study, terrain at each local site is very flat with no more than $0.5 \mathrm{~m}$ altitude difference (measured data), this means there were no considerable geographical barriers for arthropods dispersal at the local scale. Considering the dispersal abilities of carabids and ants (Schuldt and Assmann, 2011), we showed that the high dispersal abilities of carabids and ants allowed movement from one plot to the other, so that a significant spatial signal was detected for both carabids and ants (Gao et al., 2018).

At the regional scale, neither environmental factors (climate and soil variables) nor spatial factors significantly contributed to each arthropod composition and distribution. These outcomes were in opposition to our hypotheses. Climatic factors and/or geographical isolation have been supported function for community composition, distribution of spiders (Finch et al., 2008), carabids (Hendrickx et al., 2009) and ants (Liu et al., 2018) at regional scale. Other studies came to the conclusion that environmental heterogeneity, not spatial distances, control ground arthropods at the regional scale (Aisen et al., 2017). However, the shared fractions between soil and climate variables, and the shared fractions among the various factors contributed to the more than $50 \%$ of variations for all arthropods. They argued that some unmeasured spatially structured variables at the regional scale were significant but had not been taken into account. Land-use practices (Gaigher and Samways, 2014), their duration at each site (Eggleton et al., 2005), and landscape complexity (Schroder et al., 2011) affect ground arthropod compositions at the regional scale. Landscape complexity, with a mosaic of the various ways land has been utilized, has increased recently in the black soil region in northeast China (Zhang et al., 2015). Therefore, the diverse mosaics with different nonagricultural and non-urban landscape types potentially provide refugia, and a large regional species pool for arthropods (Vergnes et al., 2014), and this has been proven for species richness and composition of carabids and spiders in other studies (Schroder et al., 2011; Zhang et al., 2015; Vergnes et al., 2014; Mader et al., 2017). As already remarked earlier (Landis, 2017), we suggest that that there be more focus on landscape dynamics, fragmentations, and the landscape mosaic at regional scales.

Dispersal and land movement is very important in curbing ground arthropods disturbance brought about by farming and 

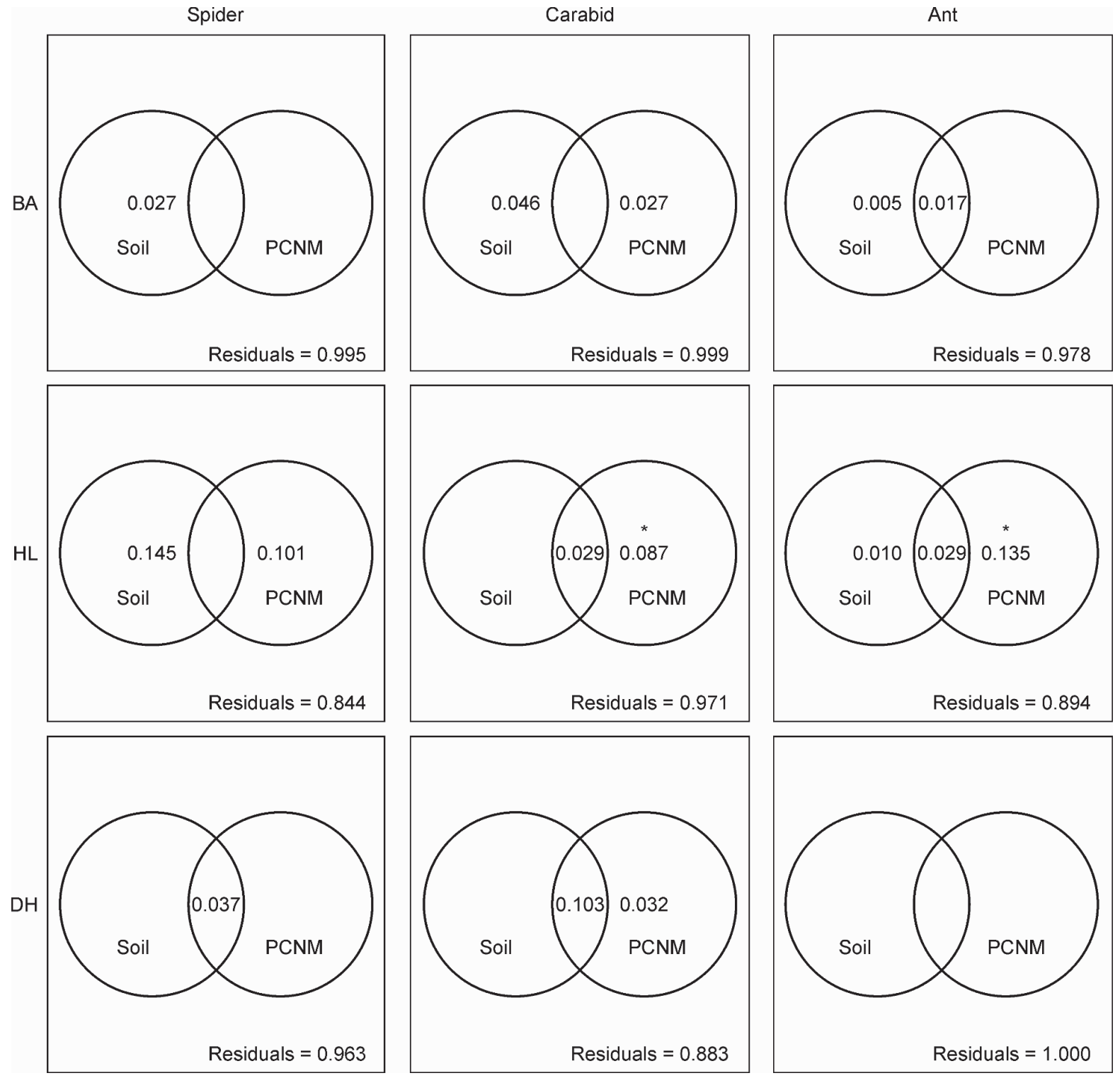

Fig. 3 Variation partitioning for spider, ant, and carabid communities in each local site tested by partial redundancy analysis (pRDA). Pure environmental, pure spatial, and shared fractions are given. Negative values are not displayed. * $p<0.05$.
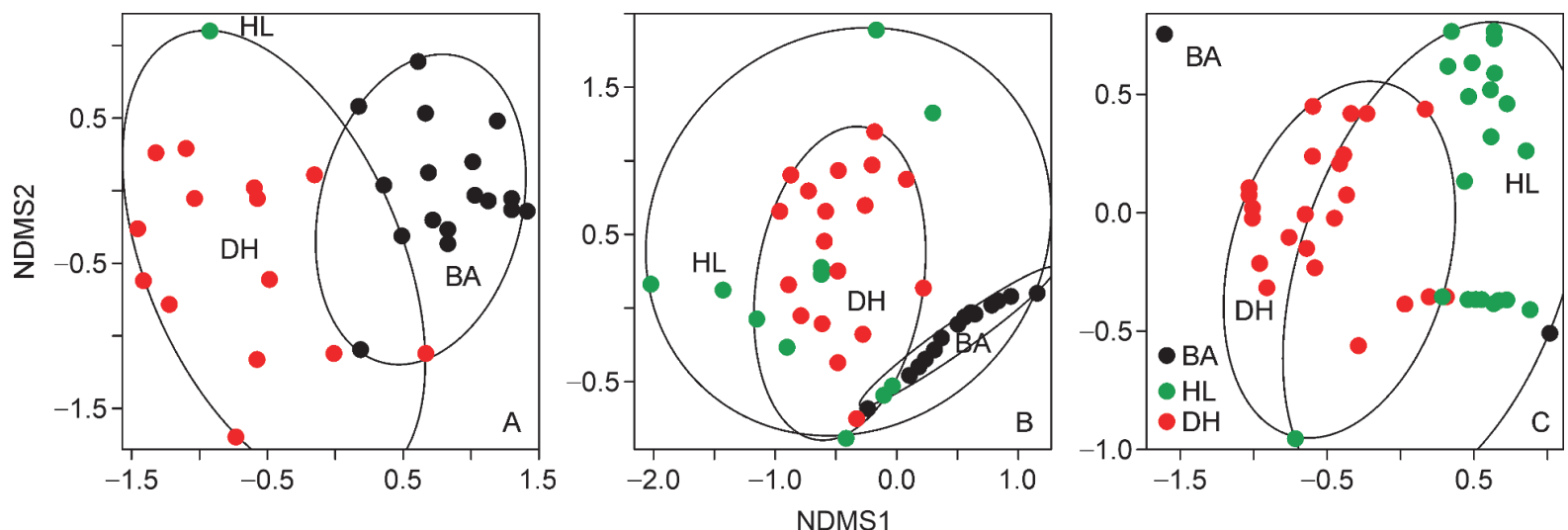

Fig. 4 Non-metric multidimensional scaling (NDMS) ordination for spiders (A), carabids (B), and ants (C) at regional scale. The ellipses envelop $95 \%$ plots of each local site. 

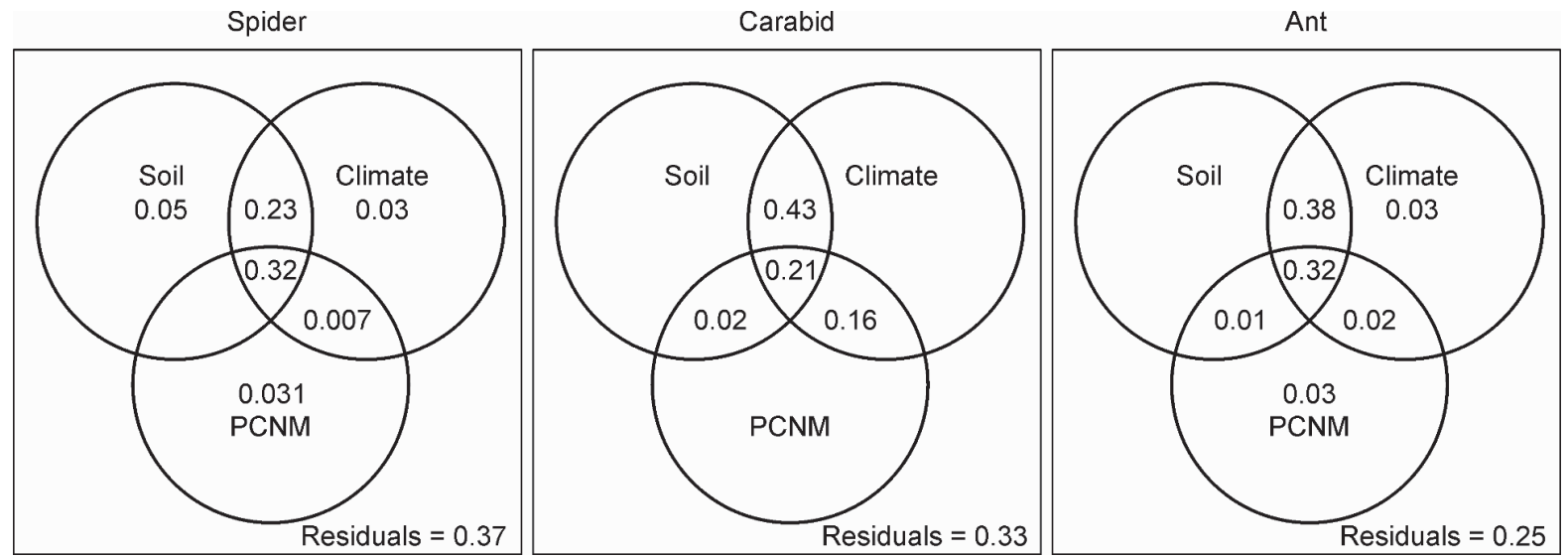

Fig. 5 Variation partitioning for spiders, carabids, and ants at regional scale tested by partial redundancy analysis (pRDA). Purely environmental, purely spatial, and shared fractions are provided. Negative values are not shown.

to search for food, mates, reproduction sites across time and space (Schellhorn et al., 2014). Ground spiders, carabids, and ants have differing feeding habits and dispersal abilities in farmland. Spiders and most carabids are predators, while other carabids and the ants are omnivore or scavengers (Chang et al., 2012; Zhang et al., 2012; Lu and Chen, 2016). Those arthropods vary significantly the way they can disperse typically from just a few meters to a few kilometers (Bonte et al., 2003; Bell et al., 2005). Carabids feed on ants, small spiders, earthworms, snails and seeds (Bonte et al., 2003; Bell et al., 2005; Kotze et al., 2011; Zhang et al., 2012; Lu and Chen, 2016). The ability of the carabids to disperse is highly dependent on the wing morphology and body size, and they can be defined as species with low, moderate, high and very high dispersal ability (Hendrickx et al., 2009). In our study area, ants were scavengers and predators that search food over a broad area and prefer insects, eggs, and larvae of spiders and carabids, honey-dew, and certain leaves. This therefore means a significant interspecific competition among macroarthropod ground predators in farmland (Schellhorn et al., 2014). Dispersal abilities, feeding preferences, and competition for resources could have adverse effects on the diversity of the ground arthropods we studied, but the details have not been well looked into. These potentially important biotic interactions probably contribute significantly to understanding the unexplained variations.

The unexplained variations were more than $80 \%$ for all arthropods at the local scale and about $37 \%$ for all arthropods at the regional scale. Therefore, there are necessary parameters that are not typically measured in geospatial species distribution studies that should be factored in at the local scale in future studies, such as unmeasured environmental variables, species dispersal abilities, biotic interactions, and stochastic processes. While at regional scale, more parameters should be considered for spatially structured environmental variables, landscape fragmentation, and species dispersal ability.

\section{Conclusions}

This research concludes that intensive agriculture practices provide a more homogeneous species richness and biodiversity of ground arthropod communities at the local scale. However, processes lead to larger species differences across different local communities. Therefore, the simplified habitat structure lowered the diversity of species at the local scale, but resulted in a relatively higher species diversity in the regional species pool. Dispersal-based factors (stochastic processes), not soil factors (deterministic processes), regulated the homogeneous community composition of carabids, spiders, and ants at the local scale. However, at the regional scale, spatially structured environmental factors were dominant. Basing our argument on this outcome, we propose that to maintain and promote regional diversity, there must be planned landscape complexity to include a non-agricultural mosaic of habitats at the regional scale.

\section{Acknowledgments}

We thank Shuhua Zhang and Lin Lin for their assistance with field and laboratory work. We thank Jiangshan Lai for his assistance with data analysis. We thank landowners for the permission and conveniences they provided. We also thank the anonymous reviewers. This work was supported by the National Natural Sciences Foundations of China (grant numbers 41430857, 41871042); and Special Foundation for National Science and Technology Basic Research Program of China (grant number 2018FY1003000).

\section{Electronic supplementary material}

Supplementary material is available in the online version of this article at http://dx.doi.org/10.1007/s42832-020-0071-1 and is accessible for authorized users. 


\section{References}

Aisen, S., Werenkraut, V., Márquez, M.E.G., Ramírez, M.J., Ruggiero, A., 2017. Environmental heterogeneity, not distance, structures montane epigaeic spider assemblages in north-western Patagonia (Argentina), Journal of Insect Conservation 21, 951-962.

Ameline, C., Puzin, C., Bowden, J.J., Lambeets, K., Verno, P., Pétillon, J., 2017. Habitat specialization and climate affect arthropod fitness: a comparison of generalist vs. specialist spider species in Arctic and temperate biomes, Biological Journal of the Linnean Society $121,592-599$.

Anderson, M.J., Crist, T.O., Chase, J.M., Vellend, M., Inouye, B.D., Freestone, A.L., Sanders, N.J., Cornell, H.V., Comita, L.S., Davies, K.F., Harrison, S.P., Kraft, N.J.B., Stegen, J.C., Swenson, N.G., 2011. Navigating the multiple meanings of $\beta$ diversity: a roadmap for the practicing ecologist, Ecology Letters 14, 19-28.

Banaszak-Cibicka, W., Żmihorski, M., 2020. Are cities hotspots for bees? Local and regional diversity patterns lead to different conclusions. Urban Ecosystems 23, 713-722.

Baselga, A., 2010. Partitioning the turnover and nestedness components of beta diversity, Global Ecology and Biogeograph 19, 134-143.

Baselga, A., Orme, D., Villeger, S., Bortoli, D., Leprieur, F., 2013. betapart: Partitioning beta diversity into turnover and nestedness components. R package version 1.3., Available at: https://cran.rproject.org/web/packages/betapart/index.html.

Bates, D.M., (2010). "Ime4: Mixed-effects modeling with R."http://rforge.r-project.org/scm/viewvc.php/ ${ }^{*}$ checkout*/www/book/front. pdf? revision $=638 \&$ root $=\operatorname{lme} 634$.

Bell, J., Bohan, D., Weyman, G., 2005. Ballooning dispersal using silk: world fauna, phylogenies, genetics and models, Bulletin of Entomological Research 95, 69-114.

Benhadi-Marín, J., Pereira, J.A., Sousa, J.P., Santos, S.A.P., 2020. Distribution of the spider community in the olive grove agroecosystem (Portugal): potential bioindicators. Agricultural and Forest Entomology 22, 10-19.

Benocci, A., Bacaro, G., Manganelli, G., 2015. Local and regional scale biodiversity patterns of forest snail assemblages in Tuscany (central Italy). Community Ecology 16, 147-155.

Blanchet, F.G., Legendre, P., Bergeron, J.A.C., He, F., 2014. Consensus RDA across dissimilarity coefficients for canonical ordination of community composition data, Ecological Monographs 84, 491-511.

Bolker, M., Brooks, M.E., Clark, C.J., Geange, S.W., Poulsen, J.R., Stevens, M.H.H., White, J.S.S., 2009. Generalized linear mixed models: a practical guide for ecology and evolution. Trends in Ecology \& Evolution 24, 127-135.

Bonte, D., Vandenbroecke, N., Lens, L., Maelfait, J., 2003. Low propensity for aerial dispersal in specialist spiders from fragmented landscapes, Proceedings Biological Sciences 270, 16011607.

Borchard, F., Buchholz, S., Helbing, F., Fartmann, T., 2014. Carabid beetles and spiders as bioindicators for the evaluation of montane heathland restoration on former spruce forests, Biological Conservation 178, 185-192.
Cerda, X., Palacios, R., Retana, J., 2009. Ant community structure in citrus orchards in the Mediterranean basin: impoverishment as a consequence of habitat homogeneity, Environmental Entomology 38, 317-324.

Chang, H., Zhang, X., Duan, M., Yu, Z., Liu, Y., 2012. Spatial distribution pattern of carabid assemblage in agricultural landscape of Miyun County, Beijing, Chinese Journal of Applied Ecology 23, 1545-1550.

Clough, Y., Holzschu, A., Gabriel, D., Purtauf, T., Kleijn, D., Kruess, A., Steffan-Dewenter, I., Tscharntke, T., 2007. Alpha and beta diversity of arthropods and plants in organically and conventionally managed wheat fields, Journal of Applied Ecology 44, 804-812.

Crist T.O., Wiens J.A., 1996. The distribution of ant colonies in a semiarid landscape: implications for community and ecosystem processes. Oikos 76, 301-311.

Crist, T.O., Veech, J.A., 2006. Additive partitioning of rarefaction curves and species-area relationships: unifying a-, b- and cdiversity with sample size and habitat area. Ecology Letters 9, 923-932.

Cui, H., Zhang, B., Yu, L., Zhu, J., He, Y., 2003. Pattern and change of black soil resources in China, Resources Science 25, 64-48.

Curry, C.J., Bai, D.J., 2015. Habitat type and dispersal ability influence spatial structuring of larval Odonata and Trichoptera assemblages, Freshwater Biology 60, 2142-2155.

Duchaufour P., 1976. Dynamics of organic matter in soils of temperate regions: Its action on pedogenesis. Geoderma 15, 31-40.

de la Flor Y.A.D., Perry K.I., Turo K.J., Parker D.M., Thompson J.L., Gardiner M.M., 2020. Local and landscape-scale environmental filters drive the functional diversity and taxonomic composition of spiders across urban greenspaces, Journal of Applied Ecology 57, 1570-1580.

Dray, S., Legendre, P., Peres-Neto, P.R., 2006. Spatial modelling: a comprehensive framework for principal coordinate analysis of neighbour matrices (PCNM). Ecological Modelling 196, 483-493.

Dunck, B.r., Schneck, F., Rodrigues, L., 2016. Patterns in species and functional dissimilarity: insights from periphytic algae in subtropical floodplain lakes, Hydrobiologia 763, 237-247.

Eggleton, P., Vanbergen, A.J., Jones, D.T., Lambert, M.C., Rockett, C., Hammond, P.M., Beccaloni, J., Marriott, D., Ross, E., Giusti, A., 2005. Assemblages of soil macrofauna across a Scottish land-use intensification gradient: influences of habitat quality, heterogeneity and area, Journal of Applied Ecology 42, 1153-1164.

Entling, W., Schmidt-Entling, M.H., Bacher, S., Brandl, R., Nentwig, W., 2010. Body size-climate relationships of European spiders, Journal of Biogeography 37, 477-485.

Eyre, M.D., McMillan, S.D., Critchley, C.N.R., 2016. Ground beetles (Coleoptera, Carabidae) as indicators of change andpattern in the agroecosystem: Longer surveys improve understanding. Ecological Indicators 68, 82-88.

Fan, R., 2013. Sequestration mechanisms of organic carbon in black soils under conservation tillage. Doctor of Philogophy, University of Chinese Academy of Sciences.

Finch, O.D., Blick, T., Schuldt, A., 2008. Macroecological patterns of spider species richness across Europe, Biodiversity \& Conservation 17, 2849-2868.

Fontana, V., Guariento, E., Hilpold, A., Niedrist, G., Steinwandter, M., 
Spitale, D., Nascimbene, J., Tappeiner, U., Seeber, J., 2020. Species richness and beta diversity patterns of multiple taxa along an elevational gradient in pastured grasslands in the European Alps. Scientific Reports 10, 12516.

Gaigher, R., Samways, M.J., 2014. Landscape mosaic attributes for maintaining groundliving spider diversity in a biodiversity hotspot, Insect Conservation and Diversity 7, 470-479.

Galle, R., Csaszar, P., Makra, T., Galle-Szpisjak, N., Ladanyi, Z., Torma, A., Ingle, K., Szilassi, P., 2018. Small-scale agricultural landscapes promote spider and ground beetle densities by offering suitable overwintering sites, Landscape Ecology 33, 1435-1446.

Gao, M., Sun, X., Qiao, Z., Hou, H., Lu, T., Wu, D., Jin, G., 2018. Distinct patterns suggest that assembly processes differ for dominant arthropods in above-ground and below-ground ecosystems, Pedobiologia 69, 17-28.

Gonçalves, F., Carlos, C., Aranha, J., Torres, L., 2018. Does habitat heterogeneity affect the diversity of epigaeic arthropods in vineyards? Agricultural and Forest Entomology 20, 366-379.

Gotelli, N.J., Colwell, R.K., 2001. Quantifying biodiversity: procedures and pitfalls in the measurement and comparison of species richness. Ecology Letters 4, 379-391.

Guo, Y., Gao, M., Liu, J., Zaitsev, A.S., Wu, D., 2019. Disentangling the drivers of ground-dwelling macro-arthropod metacommunity structure at two different spatial scales. Soil Biology \& Biochemistry $130,55-62$.

Hamaoka, H., Kamiyama, T., Hori, M., 2020. Estimating the change in regional scale distribution of seagrass and macroalgal beds using discrete local distribution data analyzed from aerial images. Ecological Research 35, 76-94.

Heino, J., Alahuhta, J., Ala-Hulkko, T., Antikainen, H., Bini, L.M., Bonada, N., Datry, T., Eros, T., Hjort, J., Kotavaara, O., Melo, A.S., Soininen, J., 2017. Integrating dispersal proxies in ecological and environmental research in the freshwater realm, Environtal Reviews 25, 334-349.

Hendrickx, F., Maelfait, J.P., Desender, K., Aviron, S., Bailey, D., Diekotter, T., Lens, L., Liira, J., Schweiger, O., Speelmans, M., Vandomme, V., Bugter, R., 2009. Pervasive effects of dispersal limitation on within- and among-community species richness in agricultural landscapes. Global Ecology and Biogeography 18, $607-616$

Jacquemin, J., Drouet, T., Delsinne, T., Roisin, Y., Leponce, M., 2012. Soil properties only weakly affect subterranean ant distribution at small spatial scales, Applied Soil Ecology 62, 163-169.

Jacquot, M., Tixier, P., Flores, O., Muru, D., Massol, F., Derepas, B., Chiroleu, F., Deguine, J.P., 2017. Contrasting predation services of predator and omnivore diversity mediated by invasive ants in a tropical agroecosystem. Basic and Applied Ecology 18, 31-39.

Koivula, M.J., 2011. Useful model organisms, indicators, or both? Ground beetles (Coleoptera, Carabidae) reflecting environmental conditions, Zookeys 100, 287-317.

Kotze, D.J., Brandmayr, P., Casale, A., Dauffy-Richard, E., Dekoninck, W., Koivula, M.J., Lövei, G.L., Mossakowski, D., Noordijk, J., Paarmann, W., Pizzolotto, R., Saska, P., Schwerk, A., Serrano, J., Szyszko, J., Taboada, A., Turin, H., Venn, S., Vermeulen, R., Zetto, T., 2011. Forty years of carabid beetle research in Europe - from taxonomy, biology, ecology and population studies to bioindication, habitat assessment and conservation, ZooKeys 100, 55-148.

Kovács-Hostyánszki, A., Elek, Z., Balázs, K., Centeri, C., Falusi, E., Jeanneret, P., Penksza, K., Podmaniczky, L., Szalkovszki, O., Báldi, A., 2013. Earthworms, spiders and bees as indicators of habitat quality and management in a low-input farming region- $A$ whole farm approach, Ecological Indicators 33, 111-120.

Kraft N. J. B., Comita L. S., Chase J. M., Sanders N. J., Swenson N. G., Crist T. O., Stegen J. C., Vellend M., Boyle B., Anderson M. J., Cornell H. B., Kendi F. Davies K. F.,Freestone A. L., Inouye B. D., Harrison S. P., Myers J. A., 2011. Disentangling the Drivers of Diversity Along Latitudinal and Elevational Gradients. Science 333, 1755-1758.

Landis, D.A., 2017. Designing agricultural landscapes for biodiversitybased ecosystem services, Basic and Applied Ecology 18, 1012.

Legendre, P., 2015. Interpreting the replacement and richness difference components of beta diversity, Global Ecology \& Biogeography 23, 1324-1334.

Legendre, P., Legendre, L., 1998. Numerical Ecology (Developments in Environmental Modelling). Elsevier Science B. V., Amsterdam, The Netherlands.

Li, X., Zhu, H.Geisen, S.Bellard, C.Hu, F.Li, H.Chen X., Liu,M. 2020. Agriculture erases climate constraints on soil nematode communities across large spatial scales. Global Change Biology 26, 919930

Li, X., Liu, Y., Duan, M., Yu, Z., Axmacher, J.C., 2018. Different response patterns of epigaeic spiders and carabid beetles to varying environmental conditions in fields and semi-natural habitats of an intensively cultivated agricultural landscape, Agriculture, Ecosystems and Environment 264, 54-62.

Lindo, Z., Winchester, N.N., 2008. Scale dependent diversity patterns in arboreal and terrestrial oribatid mite (Acari: Oribatida) communities. Ecography 31, 53-60.

Liu, C., Dudley, K.L., Econ, Z.H., Xu, E.P., 2018. Mountain metacommunities: climate and spatial connectivity shape ant diversity in a complex landscape, Ecography 41, 101-112.

Liu, C., Guénard, B., Blanchard, B., Peng, Y.Q., Economo, E.P., 2016. Reorganization of taxonomic, functional, and phylogenetic ant biodiversity after conversion to rubber plantation, Ecological Monographs 86, 215-227.

Liu, J., Gao, M., Wu, D., 2017. Characteristics of ground-dwelling soil macro-arthropod communities in a biodiversity monitoring plot of black soil cropland, northeastern China. Chinese Journal of Applied Ecology 28, 3965-3975.

Liu, Y., Yu, Z., Gu, W., Axmacher, J.C., 2006. Diversity of carabids (Coleoptera, Carabidae) in the desalinized agricultural landscape of Quzhou county, China, Agriculture, Ecosystems and Environment 113, 45-50.

Lu, Z., Chen, Y., 2016. Effects of habitat on ant functional groups: A case study of Luchun County, Yunnan Province, China, Chinese Journal of Eco-Agriculture 24, 801-810.

MacArthur, R.H., MacArthur, J.W., Preer, J., 1962. On bird species diversity. II. Prediction of bird census from habitat measurements. The American Naturalist 96, 167-174.

Mader, V., Fiedler, E.D.D., Thorn, S., Wolters, V., Birkhofer, K., 2017. Trade-offs in arthropod conservation between productive and nonproductive agri-environmental schemes along a landscape com- 
plexity gradient, Insect Conservation and Diversity 10, 236-247.

Melo A.S., Range IT.F.L.V.B., Diniz-Filho J.A.F., 2009. Environmental drivers of beta-diversity patterns in New-World birds and mammals. Ecography 32, 226-236.

Murria, C., Bonada, N., Vellend, M., Zamora-Munoz, C., AlbaTercedor, J., Sainz-Cantero, C.E., Garrido, J., Acosta, R., Alami, M.E., Barquın, J., Derka8, T., Alvarez-Cabria, M., Sainz-Bariain, M., Filipe, A.F., Vogler, A.P., 2017. Local environment rather than past climate determines community composition of mountain stream macroinvertebrates across Europe, Molecular Ecology 26, 6085-6099.

Oksanen, J., Blanchet, F.G., Kindt, R., Legendre, P., Minchin, P.R., O'Hara, R.B., Simpson, G.L., Solymos, P., Henry, M., Stevens, H., Wagner, H., 2017. "Vegan: Community Ecology Package. R package version 2.4-4. https://cran.r-project.org/web/packages/ vegan/index.html.

Pakeman, R.J., Stockan, J.A., 2014. Drivers of carabid functional diversity: abiotic environment, plant functional traits, or plant functional diversity? Ecology, 95, 1213-1224.

Pansu M., Gautheyrou J., 2007. Handbook of Soil Analysis: Mineralogical, Organic and Inorganic Methods. Springer Science \& Business Media.

Peres-Neto, P.R., Legendre, P., Dray, S., Borcard, D., 2006. Variation partitioning of species data matrices: estimation and comparison of fractions, Ecology 87, 2614-2625.

Pitta, E., Kassara, C., Trichas, A., Sfenthourakis, S., Chatzaki, M., 2017. Community variation of spiders, beetles and isopods in three small island groups of the Aegean Sea: the interplay between history and ecology, Journal of Biogeography 44, 1077-1087.

Quist, C.W., Gort, G., Mooijman, P., Brus, D.J., Elsen, S., Kostenko, O., Vervoort, M., Bakker, J., Putten, W.H., Helder, J., 2019. Spatial distribution of soil nematodes relates to soil organic matter and life strategy. Soil Biology \& Biochemistry 136, 107542.

Sasaki, T., Yoshihara, Y., 2013. Local-scale disturbance by Siberian marmots has little influence on regional plant richness in a Mongolian grassland. Plant Ecology 214, 29-34.

Schellhorn, N.A., Bianchi, F.J.J.A., Hsu, C.L., 2014. Movement of entomophagous arthropods in agricultural landscapes: links to pest suppression, Annual Review of Entomology 59 , 559-581.

Schmidt, F.A., Schoereder, J.H., Caetano, M.D.N., 2017. Ant assemblage and morphological traits differ in response to soil compaction, Insectes Sociaux 64, 219-225.

Schroder, M., Chatzaki, M., Buchholz, S., 2011. The spider fauna of the Aladjagiola wetland complex (Nestos Delta, north-east Greece): a reflection of a unique zoogeographical transition zone in Europe. Biological Journal of the Linnean Society 102, 217-233.
Schuldt, A., Assmann, T., 2011. Belowground carabid beetle diversity in the western Palaearctic - effects of history and climate on rangerestricted taxa (Coleoptera, Carabidae), ZooKeys 100, 461-474.

Simião-Ferreira, J., Nogueira, D.S., Santos, A.C.,Jr, P.D.M., Angelini, R., 2018. Multi-scale homogenization of Caddisfly Metacomminities in human-modified landscapes. Environmental Management 61, 687-699.

Sreekar, R., Koh, L.P., Mammides, C., Corlett, R.T., Goodale, E., 2020. Drivers of bird beta diversity in the Western Ghats-Sri Lanka biodiversity hotspot are scale dependent: roles of land use, climate, and distance. Oecologia 193, 801-809.

Team, T.R.D.C., 2017. R: A language and environment for statistical computing. $\mathrm{R}$ foundation for statistical computing, Version 3.4.1.

Vergnes, A., Pellissier, V., Lemperiere, G., Rollard, C., Clergeau, P., 2014. Urban densification causes the decline of ground-dwelling arthropods, Biodiversity \& Conservation 23, 1859-1877.

Widhiono, I., Pandhani, Darsono, R.D., Riwidiharso, E., Santoso, S., Prayoga, L., 2017. Ant (Hymenoptera: Formicidae) diversity as bioindicator of agroecosystem health in northern slope of Mount Slamet, Central Java, Indonesia. Biodiversitas 18, 1475-1480.

Xie, Z., 2014. Analysis of changing trend of climate elements during growing season of maize (Zea mays L.) in the past forty-one years in Hulan. Master, Northeast Agricultural University.

Yang, X., Lin, L., Zhang, X., Zhang, L., Sha, D., 2016. Spatio-temporal distribution characteristics of meso-micro soil fauna in typical cultivated blacksoil in the Song-nen plain area. Acta Ecologica Sinica 36, 3253-3260.

Zaitsev, A.S., Straalen, N.M.V., Berg, M.P., 2013. Landscape geological age explains large scale spatial trends in oribatid mite diversity. Landscape Ecology 28, 285-296.

Zhang, H., Lin, N., Bai, H., 2015. Landscape pattern anlaysis for black soil area in Songliao Plain. Journal of Anhui Agricultural Sciences 43, 22-23, 37.

Zhang, X., Chang, H., Zhang, X., Duan, M., Li, X., Yu, Z., Liu, Y., 2012. Temporal patterns of carabid beetle diversity in agro-landscape in relation to landscape structure. Chinese Journal of Ecology 31, 3127-3132.

Zheng, Y., 2012. Evaluation of groundwater resources in Bei'an of Hielongjiang province. Mater, Jilin University.

Ziesche, T.M., Roth, M., 2008. Influence of environmental parameters on small-scale distribution of soil-dwelling spiders in forests: What makes the difference, tree species or microhabitat? Forest Ecology and Management 255, 738-752.

Zuur, A.F., leno, E.N., Walker, N.J., Saveliev, A.A., Smith, G.M., 2009. Mixed Effects Models and Extensions in Ecology with R. New York, Springer Science \& Business Media. 